\title{
Treatment for ophthalmic paralysis: functional and aesthetic optimization
}

\author{
Min Ji Kim, \\ Tae Suk Oh \\ Department of Plastic and \\ Reconstructive Surgery, Asan Medical \\ Center, University of Ulsan College of \\ Medicine, Seoul, Korea
}

Facial nerve palsy has an effect on a person's well-being functionally and psychologically. Therefore, comprehensive patient management is essential. One of the most common uncomfortable and potentially debilitating features is associated with the incapacity for eye closure. Restoration of eye closure is a key consideration during the surgical management of facial palsy. In this article, we introduce simple surgical methods - which are relatively easy to learn and involve the upper and lower eyelids - for achieving eye closure. Correcting upper eyelid function involves facilitating the component of eye closure that is in the same direction as gravity and is, therefore, less complicated and favorable outcomes than correction of lower lid. Aesthetic aspects should be considered to correct the asymmetry caused by facial palsy. Lower eyelid function involves a force that opposes gravity for eye closure, which makes correction of lower eyelid ectropion more challenging than surgery for the upper eyelid, particularly in terms of effecting a sustained correction. Initially, proper ophthalmic evaluation is required, including identifying the chronicity and severity of ectropion. Also, it is important to determine whether or not lateral canthoplasty is necessary. The lateral tarsal strip procedure is commonly used for lower lid correction. However, effective lower lid correction can be achieved with better cosmesis when extensive supporting techniques are applied, including those involving cheek tissue.

Keywords: Blepharoplasty / Conditioning, eyelid / Ectropion / Esthetics / Facial paralysis / Ptosis, eyelid

\section{INTRODUCTION}

Facial palsy involves unilateral paralysis of the muscles of facial expression. Perhaps the most uncomfortable and potentially debilitating feature of facial palsy patients is the morbidity associated with the incapacity for eye closure, which directly impacts quality of life as, for example, it prevents patients from being able to read for long periods or ride a bicycle outdoors. Therefore, restoration of eye closure is of crucial importance in

\footnotetext{
Correspondence: Tae Suk Oh

Department of Plastic and Reconstructive Surgery, Asan Medical Center,

University of Ulsan College of Medicine, 88 Olympic-ro 43-gil, Songpa-gu, Seoul 05505, Korea

E-mail: tasuko@amc.seoul.kr

Received February 9, 2019 / Accepted February 18, 2019
}

the surgical management of facial palsy [1,2]. Fortunately, there are some simple surgical methods that can achieve eye closure without the need for complex surgical techniques, such as oral commissure reconstruction in facial reanimation. In this article, we describe methods to restore function of the upper eyelid and lower eyelid, respectively.

Much of the morbidity associated with facial palsy has to do with the accompanying periorbital pathology and motor dysfunction. For example, palpebral fissure widening is associated with decreased visual acuity, and orbicularis oculi dysfunction leads to failure of the lower eyelid to overcome gravity, which directly leads to corneal exposure and epiphora $[3,4]$. The lagophthalmos is further aggravated by paralytic ectropion coupled with upper and lower eyelid retraction. The aim of man- 
agement of seventh nerve palsy is restoration of ocular function while protecting the globe, maintaining visual acuity, and maximizing patient convenience. Therefore, the early stages of management aim to speed recovery and limit corneal exposure and restore the blink response $[5,6]$.

\section{UPPER EYELID CORRECTION}

Correcting upper eyelid function involves facilitating the component of eye closure that is in the same direction as gravity and is, therefore, less complicated and more frequently associated with favorable outcomes than correction of lower lid ectropion. However, we need to understand the interaction of the levator aponeurosis in functional terms. Furthermore, aesthetic aspects should be considered to improve the eye asymmetry caused by facial palsy.

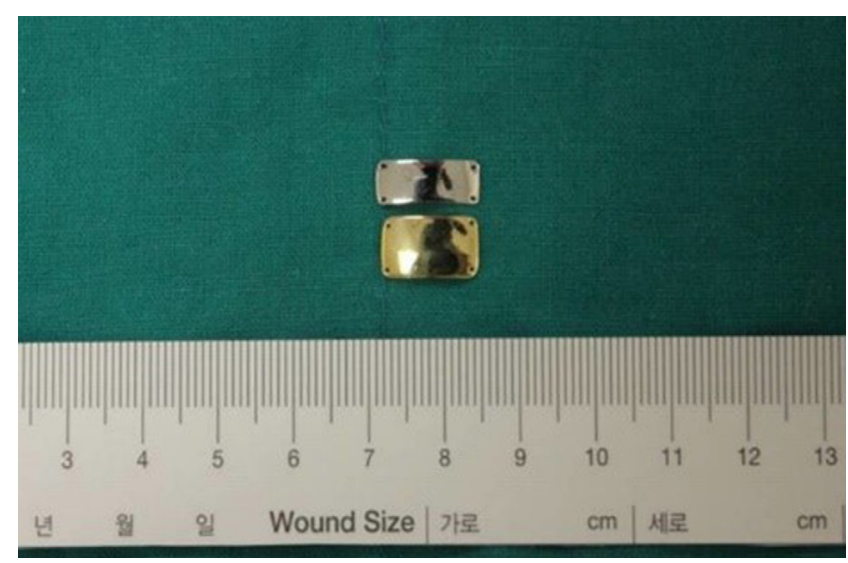

Fig. 1. Gold and platinum eyelid weights. Modified from Oh et al. Arch Plast Surg 2018;45:222-8 [2].

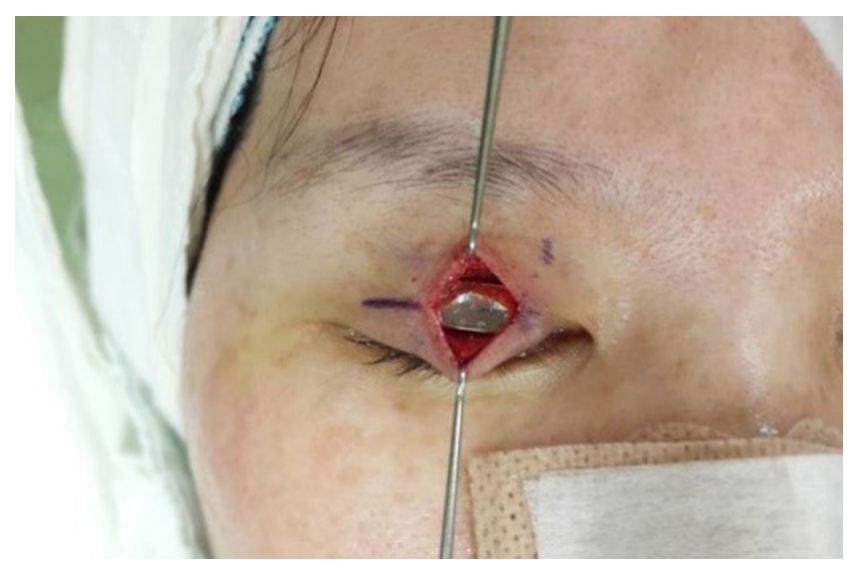

Fig. 2. Gold weight placement. Intraoperative incision design and dissection were performed to separate the levator aponeurosis and to expose the tarsal plate. Adapted from Oh et al. Arch Plast Surg 2018;45:222-8 [2].

\section{Gold weight placement}

Illig [7] reported gold weight insertion first in 1958, and this is a mainstay of surgical eyelid repair. Implantable devices are commonly used to restore dynamic lid closure. Reinforcement of eyelid weight allows the upper eyelid to close with gravity. Implants are composed of $99.99 \%$ pure gold, and their weights range from 0.6 to $1.8 \mathrm{~g}$ (Fig. 1) [2,8,9]. The possible complications should be directly managed, and these include capsule formation, allergy, migration, plate exposure, and extrusion. To avoid complications, various modifications have been proposed and studied. We prefer the method that involves insertion of a platinum implant between the levator aponeurosis and the inner septum (Figs. 2, 3) [2]. This is a technically simple procedure that produces good functional and cosmetic results; it is also associated with few complications and is reversible in the context of restored facial function (Fig. 4).

The most important component of successful correction is selection of implant weight. Patients should be in a seated position preoperatively, with the implant directly attached to upper lid skin, to allow for assessment of the weight's patient-specific appropriateness, including the effect of gravity. We prefer weights between 1.1 and $1.3 \mathrm{~g}$; however, some patients require heavier weights, and the choice of weights should be individualized. During fixation, we ensure that the medial side is securely fixed, because with the positions of the various eye-opening

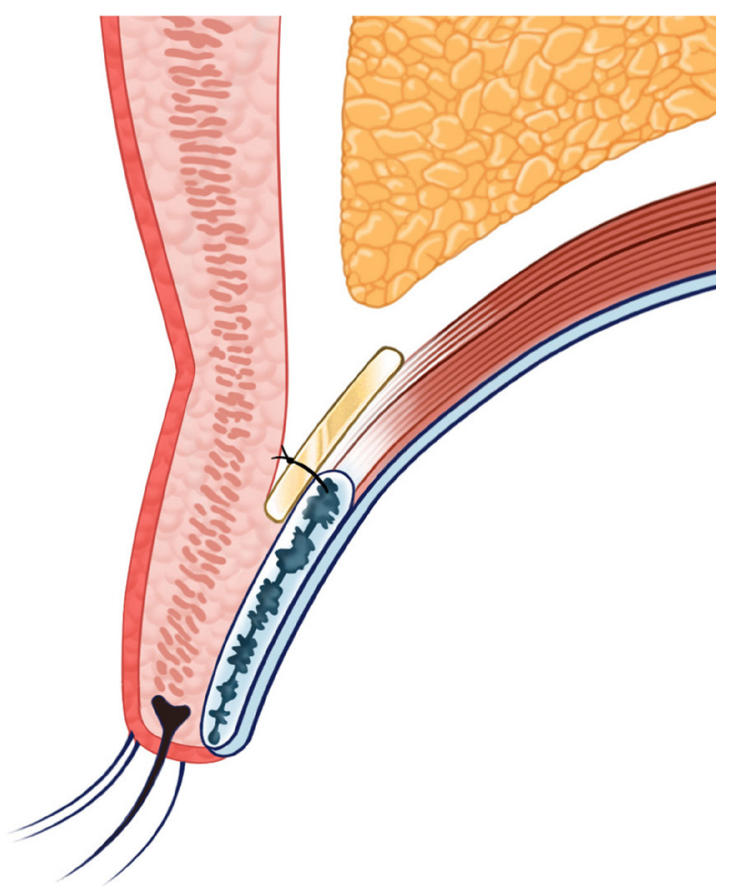

Fig. 3. Postseptal platinum weight placement. We prefer placement between the levator aponeurosis and inner septum to decrease complications, such as extrusion. 

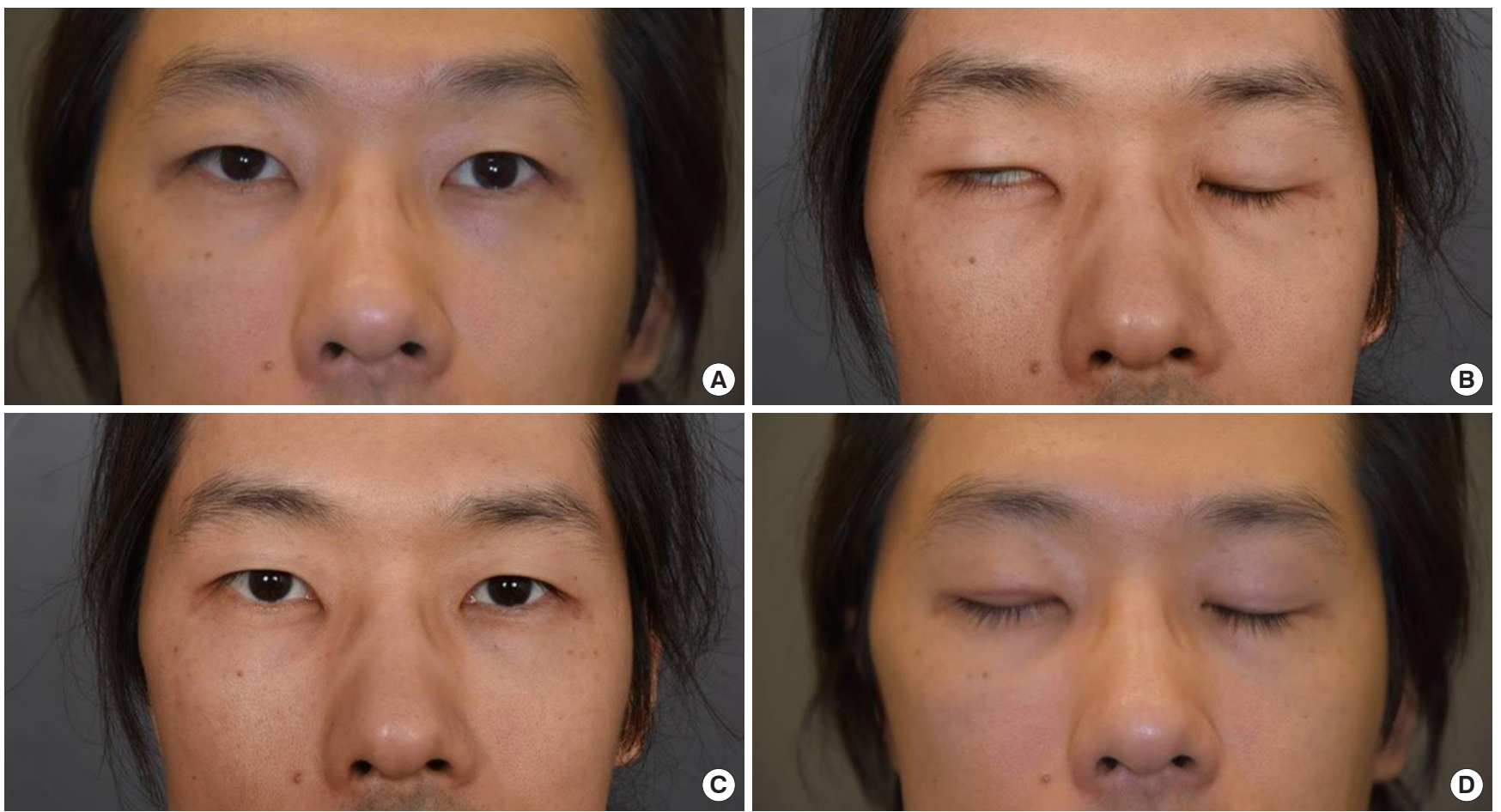

Fig. 4. A 44-year-old male patient had right-sided facial palsy for 13 years secondary to a pleomorphic adenoma resection. At the time of the tumor resection, simultaneous sural nerve and posterior auricular flaps were used. After 10 years, he was still unable to completely close his eye. Therefore, we performed platinum weight insertion (1.2 g) on his right eye, which corrected his lagophthalmos. (A) Preoperative eye open. (B) Preoperative eye closed. (C) Postoperative eye open. (D) Postoperative eye closed.
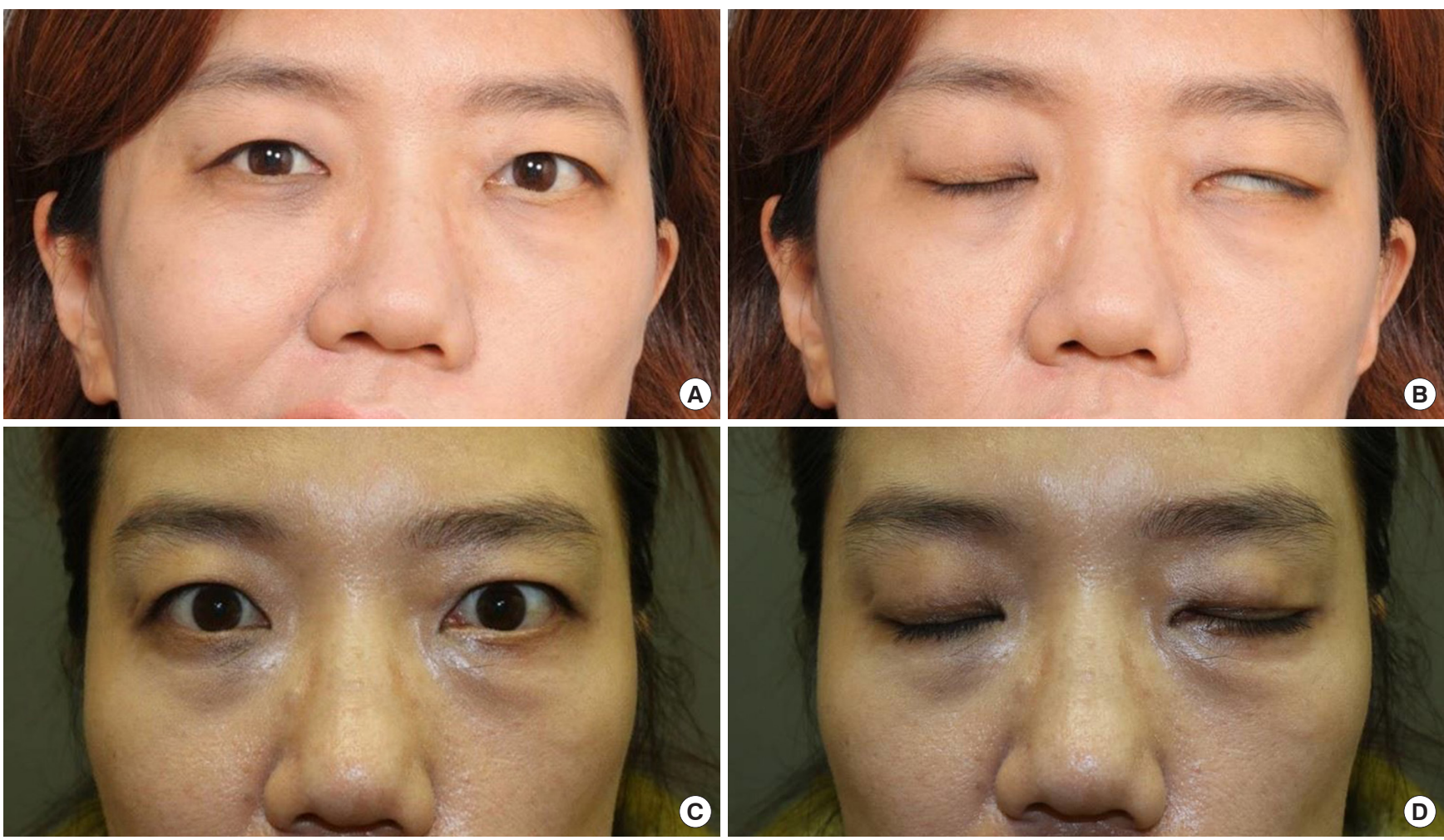

Fig. 5. A 49-year-old female patient had left-sided facial palsy, related to a hemangioma operation at 3 years of age. After platinum weight insertion, she was able to close her eye naturally, and 3 months later she underwent free functional gracilis muscle transfer for facial reanimation. (A) Preoperative eye open. (B) Preoperative eye closed. (C) Postoperative eye open. (D) Postoperative eye closed. 
muscles, insufficient eye closure may result from inadequate fixation. In this way, this can be a source of success (Fig. 5).

\section{Palpebral springs}

With gold weights, palpebral springs are commonly used in the management of ocular dysfunction [10]. In the past, tarsorrhaphy was used for static fixation of the lids for eye closure; however, modern techniques focus on lid reanimation. This dynamic perspective is meaningful. The enhanced palpebral spring technique was originated by Levine in 1990 [10]. The spring design is inspired by eyelid anatomy. The wire is placed over the midtarsus centrally, and the loop has to be positioned laterally to the orbital rim. Unlike with gold weights, this procedure can be worked with the patient in the supine position.

\section{Temporalis muscle transfer}

The temporalis muscle is innervated by fifth nerve, and it is located near the periorbital lesion. Therefore, its transposition can be used to reanimate the face and effect lid closure [11]. Distally positioned muscle fascia is transferred into the upper and lower lid to act as an encircling sling. Movement can be initiated and potentiated by the patient chewing or clenching [12].

\section{Müllerectomy}

Improvement of lid retraction can be managed by Müllerecto- my [13]. The dynamic balance between retractor and protractor tone determines upper eyelid position. Müller muscle excision can promote equilibrium between the protractor and retractor and thus reduce ocular exposure. Care was taken to avoid damage to the lacrimal gland ducts by not disturbing the lateral extensions of the Müller muscle [14].

\section{Levator lengthening}

Paul Tessier described a technique of lengthening the levator of the upper eyelid by aponeurosis interposition $[15,16]$. The technique is reliable, simple, and reproducible, allowing the weakening of the levator. Taking a temporal aponeurosis graft by coronal incision, the inferior edge of the upper eyelid levator is pulled toward the lower section to release the tissue fully. The aponeurosis graft is attached using a few separated stitches.

To optimize cosmetic outcomes, a good option can be levator lengthening combined with Müllerectomy. However, this does not fully improve orbicularis oculi function, and no opposite force is presented to the levator muscle, meaning that the lagophthalmos does not fully improve.

\section{LOWER EYELID CORRECTION}

Lower eyelid function involves a force that opposes gravity for eye closure, which makes correction of lower eyelid ectropion more challenging than surgery for the upper eyelid, particularly
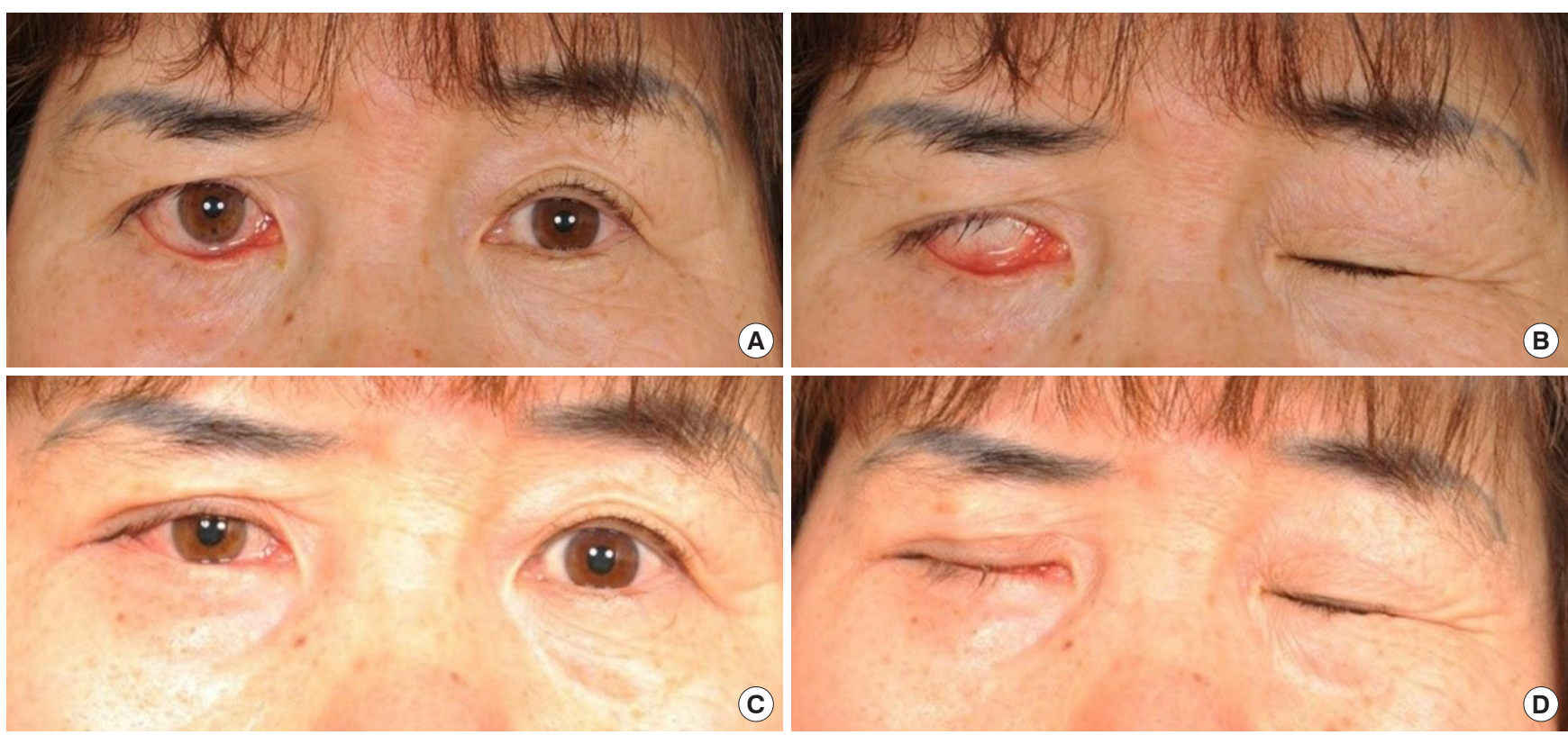

Fig. 6. A 57-year-old female patient had right-sided facial palsy for 2 years secondary to a parotid cancer resection. A mid-cheek lift with lateral canthopexy was performed. Scleral show was not seen at postoperative 13 months' follow-up. The patient also underwent platinum weight insertion on her right eye, which corrected her lagophthalmos. (A) Preoperative eye open. (B) Preoperative eye closed. (C) Postoperative eye open. (D) Postoperative eye closed. 
in terms of effecting a sustained correction. In terms of cosmesis, simple suspension of the tissue surrounding the lower lid can achieve unsatisfactory results. Thus, more extensive supporting techniques are required, including using the cheek tissue for lower lid elevation. For elderly patients, this technique can worsen lower lid ectropion due to preexisting lower lid laxity; therefore, lateral canthopexy should be performed to reduce laxity (Fig. 6).

\section{Medial and lateral canthoplasty}

The choice of appropriate surgical management for lower lid ectropion depends on the type of ectropion observed during preoperative evaluation [17]. Initially, ectropion should be classified as present or current versus potential or latent, then symptoms should be evaluated, such as lagophthalmos, lid eversion, lid malposition, and lid laxity. Ectropion with lid malposition often results in lamellar contracture which easily leads to lid retracting forces; this should be suspended using a more rigid method. This can be achieved by drilling into the lateral orbital rim or using bone anchorage equipment [18]. Patients with potent ectropion and lid laxity also present with current ectropion and lateral lid eversion but no definite lid malposition; this can be treated with lateral tarsal strip canthopexy.

\section{Tarsal strip}

The lateral tarsal strip procedure was described by Anderson and Gordy in 1979 [19]. This is focused on enhanced lower lid laxity through shortening of the lower canthus and repositioning it more laterally upward. Commonly, it requires lateral canthotomy and cantholysis together to obtain favorable cosmesis. Both lid laxity and excessive horizontal length can be corrected simultaneously, maintaining a cosmetically acceptable anatomical canthal angle and achieving a quick recovery time [20]. The

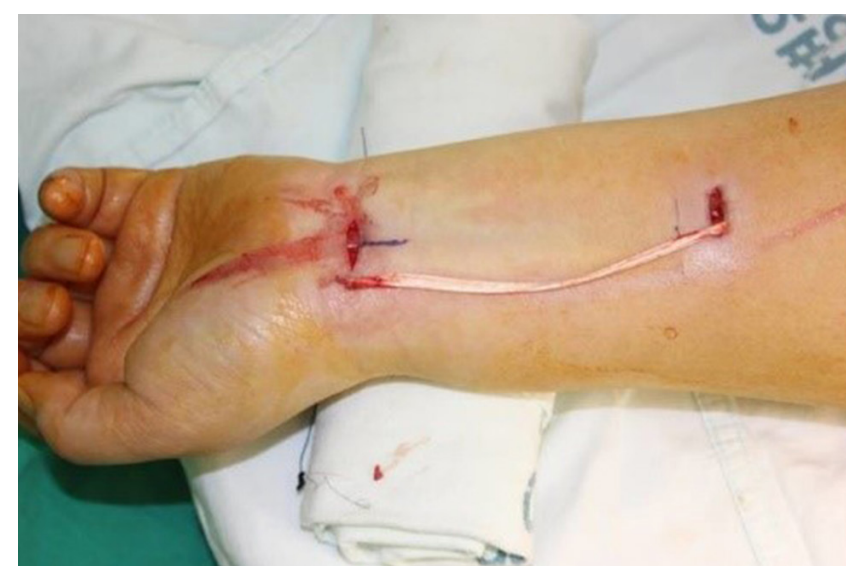

Fig. 7. Palmaris longus tendon graft harvest. procedure requires careful lateral canthal tendon dissection and good overall reconstruction of the upper and lower eyelid attachment; if these criteria are not fulfilled, this procedure may cause asymmetry in the horizontal palpebral aperture $[19,21,22]$.

\section{Kuhnt-Szymanowski procedure}

Lower lid shortening followed by a soft tissue defect commonly occur in association with ectropion. The Smith-modified Kuhnt-Szymanowski (SMKS) procedure is one of the most popular procedures to manage such presentations [23]. Consideration of the anthropometric complexity of the eyelid is essential [24]. The SMKS procedure begins with a subciliary incision beyond the lateral canthus, medial to the defect excised with a wedge shape; a posterior lamellar defect can be covered with a free chondromucosal graft from the nasal septum and a skin flap elevated superolaterally.

\section{Suspension sling}

Soft tissue suspension can be achieved using an autologous tendon graft-the palmaris longus tendon, for example - or an artificial device, such as the Mitek anchor system (Mitek Surgical Products Inc., Norwood, MA, USA). Hontanilla and GomezRuiz [25] used a strip of palmaris longus tendon and passed it through the frontal apophysis of the maxillary and lateral orbital rim using an anchoring screw. The lower lid free border should be $1.5 \mathrm{~mm}$ above the pupil (Figs. 7, 8). The correction of lower lid malposition, including scleral show and ectropion, requires effective lateral canthoplasty. Fixation, to establish both stability and favorable cosmetic outcomes, can be accomplished with the Mitek suture anchor system through a minimal incision $[26,27]$. The suspensory technique's short learning curve and quick, effective correction also provide good long-term results.

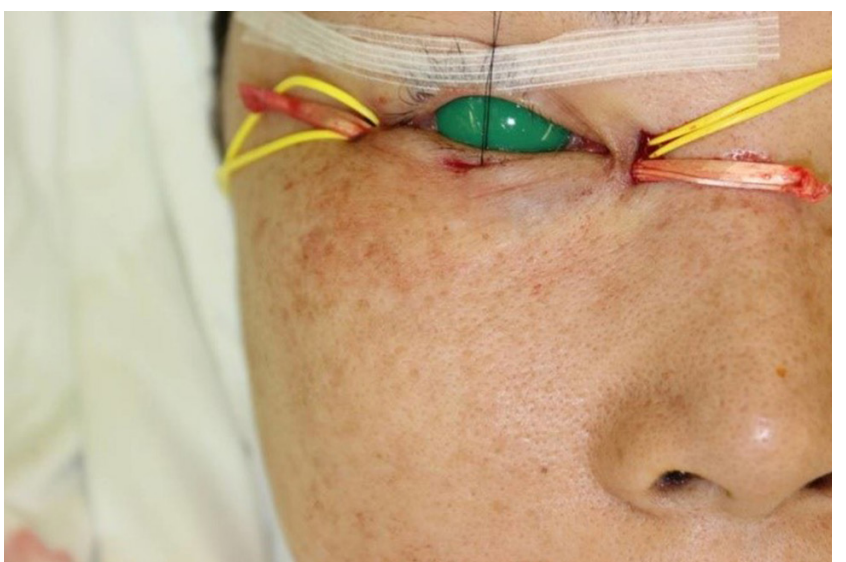

Fig. 8. Palmaris longus tendon insertion. 

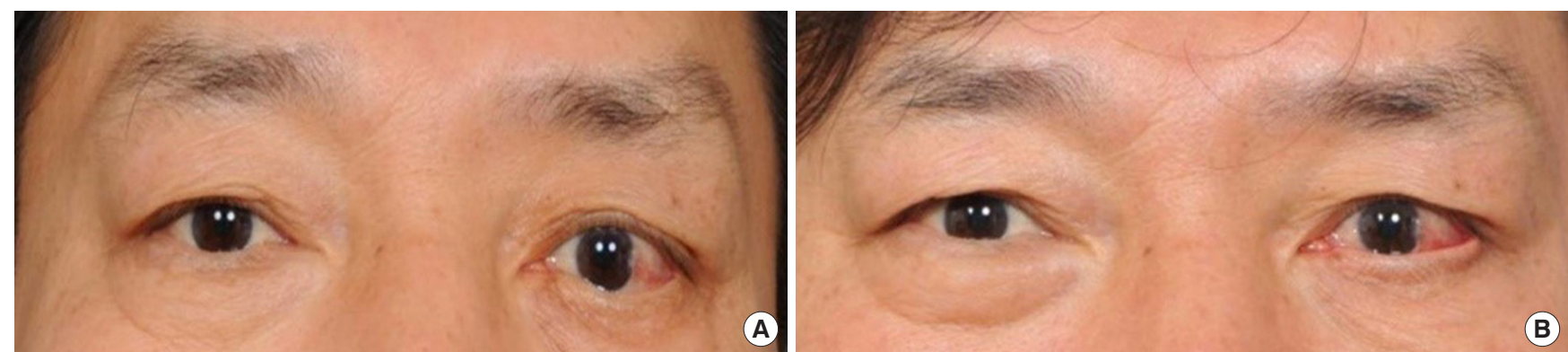

Fig. 9. A 52-year-old male patient had left-sided facial palsy for 6 years. Severe ectropion was observed. After a mid-cheek lift was performed, improvement of scleral show proceeded. (A) Preoperative. (B) Postoperative 15 months.

\section{Mid-cheek lift}

The mid-cheek lift technique minimizes the required amount of tension on the tissue by fixating it in the opposite direction of the force of gravity. The senior author of this article compared the effectiveness of the suspension sling versus lower eyelidsupporting mid-cheek lift techniques [28]. The mid-cheek lift group showed the greatest change in the ratio between the distance between the center of the pupil and the eyelid margin on the paralyzed side to that on the normal side. Therefore, we prefer the mid-cheek lift for lower lid retraction (Fig. 9). After dissection, the exposed malar fat pad should be fixed on the medial and lateral sides of the periosteum and the exposed orbicularis oculi muscle fixed to the inner part of the lateral orbital wall.

\section{CONCLUSION}

Facial palsy treatment requires a multidisciplinary approach. Patients experiencing multiple symptoms, especially eye discomfort, should not be neglected. Active surgical interventions improve both cosmesis and quality of life. There are various approaches to correcting both the upper and lower lid. Patient age, degree of lagophthalmos, orbicularis function, and existing period of facial palsy, should all be considered. Functionally proper enhancement of eye closure ability and symmetric and restoration of eye cosmesis can be achieved by selecting the appropriate techniques. Furthermore, we believe eyelid reanimation in conjunction with facial reanimation can achieve excellent results.

\section{NOTES}

\section{Conflict of interest}

No potential conflict of interest relevant to this article was reported.

\section{Ethical approval}

This study was approved by the Institutional Review Board of Asan Medical Center (IRB No. 2019-0166) and performed in accordance with the principles of the Declaration of Helsinki. Written informed consent was obtained.

\section{Patient consent}

The patients provided written informed consent for the publication and the use of their images.

\section{ORCID}

Min Ji Kim https://orcid.org/0000-0002-0723-4382

Tae Suk Oh https://orcid.org/0000-0001-8174-8915

\section{REFERENCES}

1. Alsuhaibani AH. Facial nerve palsy: providing eye comfort and cosmesis. Middle East Afr J Ophthalmol 2010;17:142-7.

2. Oh TS, Min K, Song SY, Choi JW, Koh KS. Upper eyelid platinum weight placement for the treatment of paralytic lagophthalmos: a new plane between the inner septum and the levator aponeurosis. Arch Plast Surg 2018;45:222-8.

3. Rahman I, Sadiq SA. Ophthalmic management of facial nerve palsy: a review. Surv Ophthalmol 2007;52:121-44.

4. Arrigg P, Miller D. A new lid sign in seventh nerve palsy. Ann Ophthalmol 1985;17:43-5.

5. Seiff SR, Chang J. Management of ophthalmic complications of facial nerve palsy. Otolaryngol Clin North Am 1992;25:669-90.

6. Seiff SR, Chang JS Jr. The staged management of ophthalmic complications of facial nerve palsy. Ophthalmic Plast Reconstr Surg 1993;9:241-9.

7. Illig KM. A new method of lagophthalmos surgery. Klin Monbl Augenheilkd Augenarztl Fortbild 1958;132:410-1.

8. Chapman P, Lamberty BG. Results of upper lid loading in the treatment of lagophthalmos caused by facial palsy. Br J Plast Surg 1988;41:369-72. 
9. Snyder MC, Johnson PJ, Moore GF, Ogren FP. Early versus late gold weight implantation for rehabilitation of the paralyzed eyelid. Laryngoscope 2001;111:2109-13.

10. Levine RE, Shapiro JP. Reanimation of the paralyzed eyelid with the enhanced palpebral spring or the gold weight: modern replacements for tarsorrhaphy. Facial Plast Surg 2000;16: 325-36.

11. May M, Drucker C. Temporalis muscle for facial reanimation: a 13-year experience with 224 procedures. Arch Otolaryngol Head Neck Surg 1993;119:378-82.

12. Tate JR, Tollefson TT. Advances in facial reanimation. Curr Opin Otolaryngol Head Neck Surg 2006;14:242-8.

13. Hassan AS, Frueh BR, Elner VM. Mullerectomy for upper eyelid retraction and lagophthalmos due to facial nerve palsy. Arch Ophthalmol 2005;123:1221-5.

14. Morton AD, Elner VM, Lemke BN, White VA. Lateral extensions of the Muller muscle. Arch Ophthalmol 1996;114:14868.

15. Asik MD, Yaprak B, Guven E, Karabulut AB, Guclu B. A device for the functional improvement of lagophthalmos. J Craniofac Surg 2013;24:1478-82.

16. Guillou-Jamard MR, Labbe D, Bardot J, Benateau H. Paul Tessier's technique in the treatment of paralytic lagophthalmos by lengthening of the levator muscle: evaluation of 29 cases. Ann Plast Surg 2011;67:S31-5.

17. Baek S, Chung JH, Yoon ES, Lee BI, Park SH. Algorithm for the management of ectropion through medial and lateral canthopexy. Arch Plast Surg 2018;45:525-33.

18. McCord CD, Boswell CB, Hester TR. Lateral canthal anchoring. Plast Reconstr Surg 2003;112:222-37.
19. Anderson RL, Gordy DD. The tarsal strip procedure. Arch Ophthalmol 1979;97:2192-6.

20. Olver JM. Surgical tips on the lateral tarsal strip. Eye (Lond) 1998;12 (Pt 6):1007-12.

21. Ho SF, Pherwani A, Elsherbiny SM, Reuser T. Lateral tarsal strip and quickert sutures for lower eyelid entropion. Ophthalmic Plast Reconstr Surg 2005;21:345-8.

22. Vick VL, Holds JB, Hartstein ME, Massry GG. Tarsal strip procedure for the correction of tearing. Ophthalmic Plast Reconstr Surg 2004;20:37-9.

23. Tucker SM, Santos PM. Survey: management of paralytic lagophthalmos and paralytic ectropion. Otolaryngol Head Neck Surg 1999;120:944-5.

24. Hayashi A, Mochizuki M, Kamimori T, Horiguchi M, Tanaka R, Mizuno H. Application of Kuhnt-Szymanowski procedure to lower eyelid margin defect after tumor resection. Plast Reconstr Surg Glob Open 2017;5:e1230.

25. Hontanilla B, Gomez-Ruiz R. Surgical correction of lower eyelid paralysis with suture screw anchors. J Plast Reconstr Aesthet Surg 2009;62:1598-601.

26. Alfano C, Chiummariello S, Monarca C, Scuderi N, Scuderi G. Lateral canthoplasty by the Micro-Mitek Anchor System: 10year review of 96 patients. J Oral Maxillofac Surg 2011;69:17459.

27. Bartsich S, Swartz KA, Spinelli HM. Lateral canthoplasty using the Mitek anchor system. Aesthetic Plast Surg 2012;36:3-7.

28. Min K, Oh TS. Quantitative analysis of paralyzed lower eyelid elevation technique: suspension sling vs supporting midcheek lift. Plast Reconstr Surg. Forthcoming 2019. 